九州大学学術情報リポジトリ

Kyushu University Institutional Repository

\title{
Protective Effect of $\kappa$-Carrageenan against Bacterial Infections in Carp Cyprinus carpio
}

Fujiki, Kazuhiro

Laboratory of Marine Biochemistry, Faculty of Agriculture, Kyushu University

Shin, Dong-Ho

Laboratory of Marine Biochemistry, Faculty of Agriculture, Kyushu University

Nakao, Miki

Laboratory of Marine Biochemistry, Faculty of Agriculture, Kyushu University

Yano, Tomoki

Laboratory of Marine Biochemistry, Faculty of Agriculture, Kyushu University

https://doi.org/10.5109/24198

出版情報：九州大学大学院農学研究院紀要. 42 (1/2)，pp.113-119，1997-12. Kyushu University バージョン：

権利関係 : 


\title{
Protective Effect of $\kappa$-Carrageenan against Bacterial Infections in Carp Cyprinus carpio
}

\author{
Kazuhiro Fujiki, Dong-Ho Shin, Miki Nakao \\ and Tomoki Yano \\ Laboratory of Marine Biochemistry, Faculty of Agriculture, Kyushu \\ University, Fukuoka 812-81, Japan \\ (Received April 30,19.97 and accepted August 25, 1.997)
}

\begin{abstract}
$A$ hot-water extract of tsunomata Chondrus ocellatus was found to contain polysaccharide(s) which showed immunoenhancing activity in fish. In order to identify the effective component, the hot-water extract of tsunomata was fractionated and $0.3 \mathrm{MKCl}$ insoluble and -soluble fractions (Fractions I and II) were evaluated for their potential to enhance protection against Edwardsiellatarda and Aeromonas hydrophila infections in carp. Intraperitoneal injection of Fraction I (2-3 $\mathrm{mg} / 100 \mathrm{~g}$ body weight) 6 and 3 days prior to challenge with the pathogenic bacteria resulted in significantly greater survival than that of the control fish. On the other hand, Fraction II was not effective against the pathogenic bacteria at any dose. Chemical and physicochemical analyses revealed that Fraction I was $\kappa$-carrageenan containing a trace quantity of $\iota$-carrageenan.
\end{abstract}

\section{INTRODUCTION}

It has been shown that 1,6-branched- $\beta$-1,3-glucans obtained from fungi (Lentinus edodes, Schizophyllum commune and Sclerotium glucanicum) enhanced the resistance of carp Cyprinus carpio to Edwardsiella tarda and Aeromonas hydrophila infections through the activation of the non-specific immune system (Yano et al., 1989, 1991; Mangindaan, 1992). A similar observation was made by Robertsen et al. (1990), who reported that a $\beta$-1,3-glucan (M-Glucan) obtained from baker's yeast Saccharomyces cerevisiae enhanced protection against Yersinia ruckeri, Vibrio anguillarum and Vibrio salmonicida in Atlantic salmon Salmo salar.

Recently, a hot-water extract of tsunomata Chondrus ocellatus was found to contain polysaccharide(s) with similar immunostimulating activity (Fujiki et al., 1993). This study was undertaken to identify the effective component(s) in the extract.

\section{MATERIALS AND METHODS}

\section{Fractionation of the hot-water extract of tsunomata}

Tsunomata (Fig. 1) was collected on Koinoura beach, Fukuoka Prefecture in May 1994. The algae containing both gametophytes and tetrasporophytes were washed with running tap water to remove any foreign substances, then lyophilized and milled.

To the milled tsunomata $(5.0 \mathrm{~g})$, was added $300 \mathrm{ml}$ of deionized water and the suspension was heated in boiling water for $3 \mathrm{~h}$ and centrifuged while hot at 7,000 Xg for $20 \mathrm{~min}$. The supernatant was lyophilized and defatted with acetone in a Soxhlet extractor. Fractionation of the hot-water extract thus obtained was performed according 


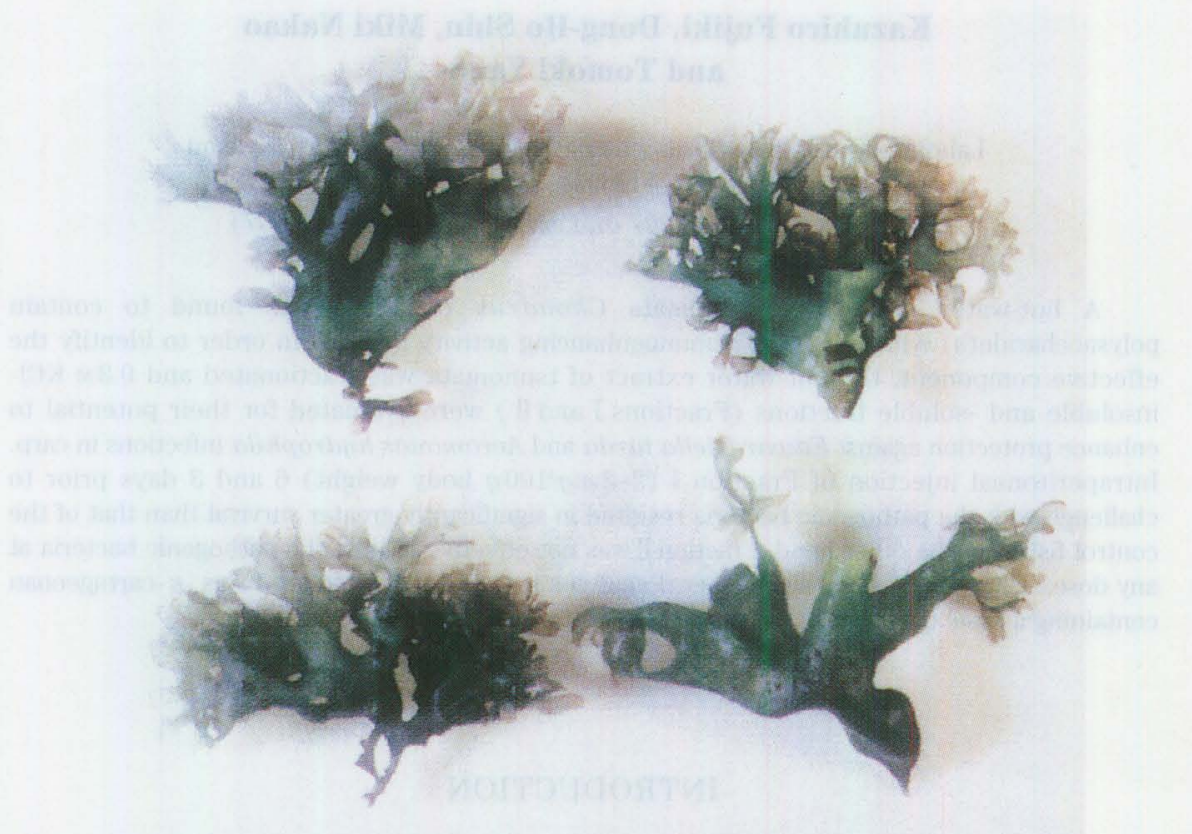

Fig. 1. Tsunomata Chondrus ocellatus which was collected on Koinoura beach, Fukuoka Prefecture in May 1994

to the methods of Craigie and Leigh (1978) and Painter (1965). Briefly, the hot-water extract was dissolved in water maintained at $80-85^{\circ} \mathrm{C}$ at a concentration of $0.22 \%$ and to this was added $1 / 10$ volume of $3 \mathrm{M} \mathrm{KCl}$ drop by drop with stirring. The solution was kept at $0^{\circ} \mathrm{C}$ for $1 \mathrm{~h}$, followed by centrifugation at $25,000 \times \mathrm{g}$ for $30 \mathrm{~min}$. The precipitate was washed three times with ice-cold $0.3 \mathrm{M} \mathrm{KCl}$, suspended in $1 \%$ sodium acetate and dialyzed against the same buffer until gelatinous particles dissolved. The solution was then dialyzed against water and lyophilized (Fraction I ). The supernatant and the washings were combined and successively dialyzed against $1 \%$ sodium acetate and water and then lyophilized (Fraction II).

\section{Fish}

Carp (26-32g) were purchased from a fish farm in Kumamoto Prefecture and acclimated for 2 weeks at $22-23^{\circ} \mathrm{C}$ in $60 \ell$ aquaria filled with recirculating well water. During acclimation and experiments, fish were fed with commercial pellets (Nippon Formula Feed Mfg. Co. Ltd.).

\section{Bacteria}

An Edwardsiella tarda strain (NG8104), which was isolated from diseased flounder 
Paralichthys olivaceus, was kindly donated by Dr. T. Kitao, Miyazaki University, Japan. An Aeromonas hydrophila strain (KAH8501), which was isolated from eel Anguilla japonica, was donated by Dr. T. Sasaki, Kitasato Research Institute, Chiba, Japan. The virulence of these bacteria was enhanced by passing through carp three times. Then the isolates were suspended in $3 \%$ skimmed milk containing $5 \%$ glucose $(\mathrm{pH} 7.4)$ and stored at $-80^{\circ} \mathrm{C}$ until used.

An inoculum of $E$. tarda was prepared by growing the stock isolate on heart infusion (HI) agar (Nissui Pharmaceutical Co. Ltd., Tokyo) at $36^{\circ} \mathrm{C}$ for $20 \mathrm{~h}$ and suspending the cells in sterile saline at $2.0 \times 10^{8}$ colony forming units (CFU) $/ m l$. An A. hydrophila inoculum was prepared by growing the bacteria on $\mathrm{HI}$ agar at $22-23^{\circ} \mathrm{C}$ for $17 \mathrm{~h}$ and suspending in sterile saline at a concentration of $5.0 \times 10^{7} \mathrm{CFU} / \mathrm{ml}$.

\section{Challenge test}

Fish were injected intraperitoneally (i.p.) with Fraction I or Fraction $I$ at doses of 2 and $3 \mathrm{mg} / 100 \mathrm{~g}$ body weight, or with the hot-water extract of tsunomata at a dose of $5 \mathrm{mg} / 100 \mathrm{~g}$ body weight on days 1 and 4 . On day 7 , the fish were challenged with $E$. tarda (2.0 $\times 10^{8} \mathrm{CFU} / 100 \mathrm{~g}$ body weight) or $A$. hydrophila $\left(5.0 \times 10^{7} \mathrm{CFU} / 100 \mathrm{~g}\right.$ body weight).

\section{Analytical methods}

3,6-Anhydrogalactose was determined by the method of Yaphe and Arsenault (1965), using D-fructose as a standard. Ester sulfate was determined according to Kawai et al. (1969) after hydrolysis with $1 \mathrm{~N} \mathrm{HCl}$ at $100^{\circ} \mathrm{C}$ for $6.5 \mathrm{~h}$. Total nitrogen was measured with a CHN corder (Model MT-3, Yanagimoto Mfg. Co. Ltd., Kyoto). IR spectrum was recorded by the $\mathrm{KBr}$ tablet method using a Fourier-transform IR spectrophotometer (Model FT/IR700 , Jasco International Co., Tokyo).

\section{Statistics}

The significance of survival rate in the challenge tests was evaluated by Fisher's exact probability test with a significance level of $P<0.05$.

\section{RESULTS}

\section{Fractionation of the hot-water extract of tsunomata}

The hot-water extract $(3.13 \mathrm{~g})$ of tsunomata was separated into two fractions, $0.3 \mathrm{M}$ $\mathrm{KCl}$-soluble and insoluble fractions. Fraction I $(1.98 \mathrm{~g})$ was obtained from the insoluble fraction and Fraction $I(0.89 \mathrm{~g})$ from the soluble fraction.

\section{Effects of Fractions I and II on the survival of carp after challenged with $E$. tarda}

Groups of 20 fish each were injected i.p. with Fraction I or Fraction II at doses of 2 and $3 \mathrm{mg} / 100 \mathrm{~g}$ body weight, or with the hot-water extract of tsunomata at a dose of $5 \mathrm{mg} / 100 \mathrm{~g}$ body weight on days 1 and 4 . The control fish received saline alone. On day 7 , all fish were challenged with $E$. tarda and survival rate of each group was monitored for 7 days.

As shown in Fig. 2, injections of Fraction I resulted in $60-75 \%$ survival after 


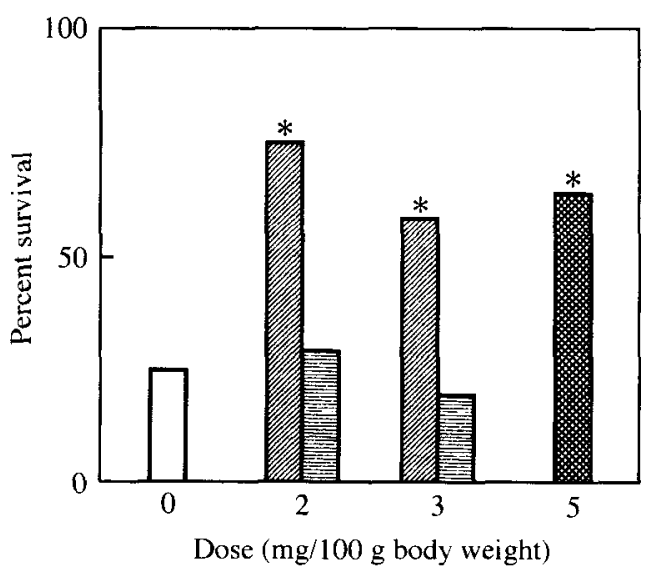

Fig. 2. Effects of Fraction I and Fraction $\Pi$ on survival rate of carp after challenged with $E$. tarda. Data represent the means of 20 fish.

, Fraction I ; Fraction II ; hot-water extract of tsunomata;

$\square$, saline alone (control). * Significantly different from the control group.

challenged with $E$. tarda. The survival rate was significantly higher than that of the control fish, and were nearly equal to that of the fish which received the hot-water extract of tsunomata ( $5 \mathrm{mg} / 100 \mathrm{~g}$ body weight). On the other hand, Fraction II was not effective at any dose.

\section{Effect of Fraction I on survival of carp after challenged with $A$. hydrophila}

Groups of 20 fish were injected with Fraction I at doses of 2 and $3 \mathrm{mg} / 100 \mathrm{~g}$ body

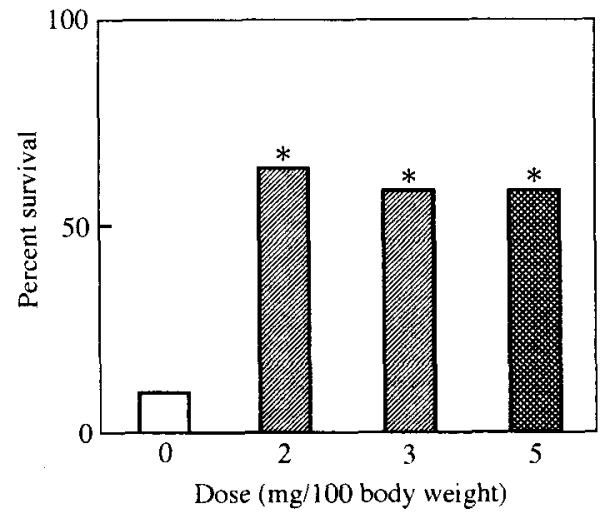

Fig. 3. Effect of Fraction I on survival rate of carp after challenged with $A$. hydrophila. Data rpresent the means of 20 fish. , Fraction I; hot-water extract of tsunomata; $\square$, saline alone (control). * Significantly different from the control group. 
weight, or with the hot water extract of tsunomata at a dose of $5 \mathrm{mg} / 100 \mathrm{~g}$ body weight on days 1 and 4 . The control fish received saline alone. On day 7, all fish were challenged with $A$. hydrophila and survival rate of each group was recorded for 7 days.

As seen in Fig. 3, injections of Fraction I resulted in 60-65\% survival after challenged with $A$. hydrophila. The survival rate was significantly higher than that of the control fish, and were nearly equal to that of the fish which received the hot-water extract of tsunomata ( $5 \mathrm{mg} / 100 \mathrm{~g}$ body weight).

\section{Identification of Fraction I}

Component analysis (Table 1) revealed that Fraction I contained 3,6-anhydrogalactose (23.8\%) and ester sulfate (28.7\%). The data coincided with those of $\kappa$ - or $\iota$-carrageenan (McCandless et al., 1983). The IR spectrum of Fraction I showed two large peaks at $845 \mathrm{~cm}^{-1}$ and $930 \mathrm{~cm}^{-1}$ which are characteristic of C4-sulfate and 3,6-anhydrogalactose of $\kappa$-carrageenan, respectively (Fig. 4), and a small peak at $805 \mathrm{~cm}^{-1}$ which is characteristic of C2-sulfate on anhydrogalactose of $\iota$-carrageenan (McCandless et al., 1983).

These results suggest that Fraction $\mathrm{I}$ is $\kappa$-carrageenan containing a trace quantity of ८-carrageenan.

Table 1. Yield and composition analyses of the $\kappa$-carrageenan fraction obtained from the hot-water extract of $C$. ocellatus.

\begin{tabular}{cccc}
$\begin{array}{c}\text { Yield } \\
(\%)\end{array}$ & $\begin{array}{c}3,6 \text {-anhydrogalactose } \\
(\%)\end{array}$ & $\begin{array}{c}\text { Ester sulfate } \\
(\%)\end{array}$ & $\begin{array}{c}\text { Total nitrogen } \\
(\%)\end{array}$ \\
\hline 63.2 & 23.8 & 28.7 & 0.2 \\
\hline
\end{tabular}

* Percentage in the hot-water extract.

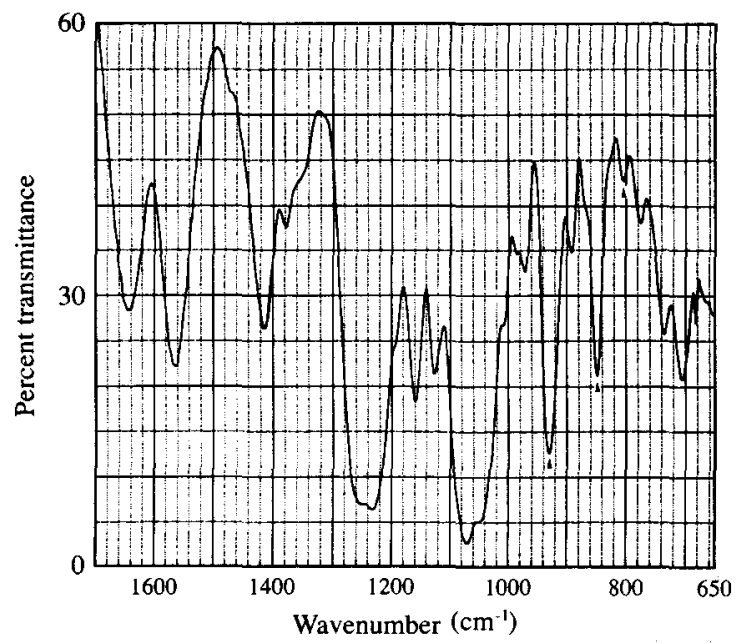

Fig. 4. Infrared (IR) absorption spectrum of $\kappa$-carrageenan. The spectrum was measured by the $\mathrm{KBr}$ tablet method using a Fourier transform IR spectrophotometer. 


\section{DISCUSSION}

In our previous paper (Fujiki et al., 1993), the hot-water extracts from 7 species of red algae (Porphyra yezoensis, Hyalosiphonia caespitosa, Gloiopeltis complanata, $G$. furcata, Carpopeltis affnis, C. ocellatus and Hypnea charoides) significantly elevated the survival rate of carp after challenged with $E$. tarda, and especially the fish which were administered with the extract of $C$. ocellatus (tsunomata) showed the highest survival. Tsunomata is a seaweed which can be found on almost every seashore in Japan and is known to contain considerable amount of carrageenan.

The present work demonstrated that $\kappa$-carrageenan was the effective component in the hot-water extract of tsunomata which enhanced the resistance of carp against $E$. tarda in the previous paper (Fujiki et al., 1993). Carrageenans are linear sulfated poly-Dgalactans composed of repeating disaccharide units and can be classified into 7 types $(\kappa-$, $\mu_{-}, \nu_{-}, \iota_{-}, \lambda-, \xi$ - and $\pi$-types) by their molecular structures (Fig. 5) (Craigie, 1990).

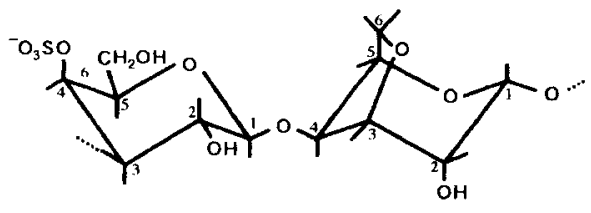

$\kappa$-carrageenan
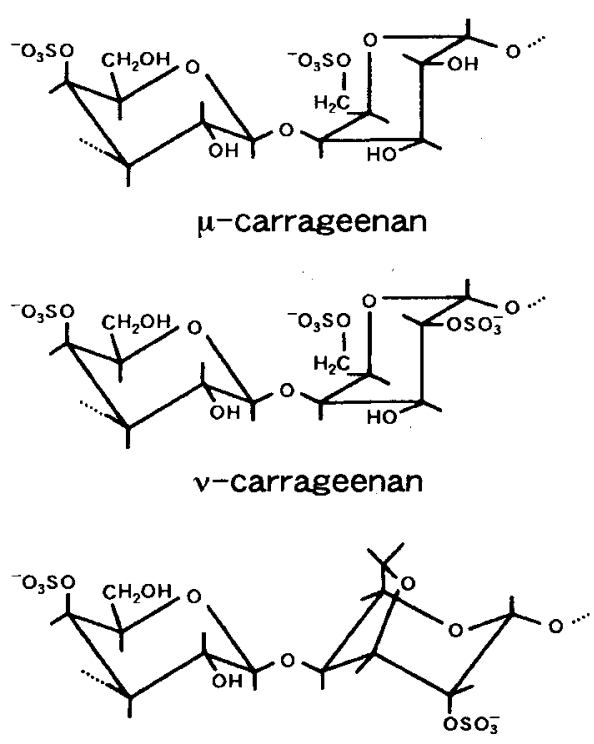

t-carrageenan
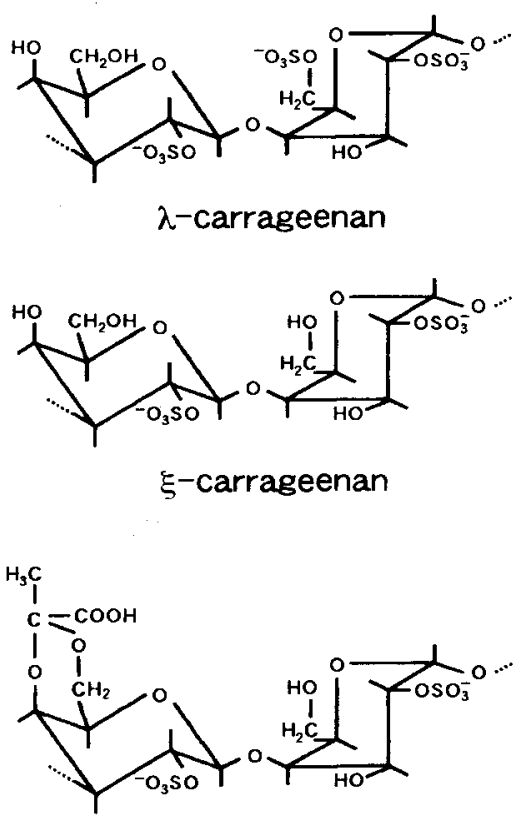

$\pi$-carrageenan

$\lambda$-carrageenan family

$\kappa$-carrageenan family

Fig. 5. Repeating disaccharide structures of 7 types of carrageenans. 
The $\kappa$-carrageenan obtained in the present experiment contained a trace quantity of $\iota$-carrageenan and any further purification could not be done. Both $\kappa$-and $\iota$-carrageenans are composed of $\beta$-3-linked D-galactose-4-sulfate and $\alpha$-4-linked 3,6-anhydro-D-galactose (Fig. 5), and the difference is the presence of ester sulfate at C2 of 3,6-anhydro-Dgalactose residue in $\iota$-carrageenan (Craigie and Leigh, 1978). McCandless et al. (1983) reported that some tsunomata contain $\kappa$-carrageenan alone and some others contain $\kappa$ ( 1 )-hybrid carrageenan. On the other hand, Craigie (1990) reported that it is often difficult to determine whether or not the two types of carrageenans occur as separate chemical entities or whether they are glycosidically linked in a single hybrid macromolecule. Therefore, a possibility remains that Fraction I is $\kappa$-carrageenan partly containing 3,6-anhydro-D-galactose 2 -sulfate residue in the molecule.

In the challenge test, the mean survival rate of fish which received $2 \mathrm{mg} / 100 \mathrm{~g}$ body weight of $\kappa$-carrageenan was slightly higher than that which received $3 \mathrm{mg} / 100 \mathrm{~g}$ body weight of $\kappa$-carrageenan. This implies the presence of an optimum dosage range in $\kappa$ carrageenan.

$\kappa$-Carrageenan appears to have exerted its effect through the activation of the nonspecific immune system of carp, since it was effective against two distinct pathogens, $E$. tarda and $A$. hydrophila, and the fish acquired their resistance to the pathogenic bacteria within a few days, earlier than would be expected if the specific immune response was involved.

\section{REFERENCES}

Craigie, J. S. 1990 Cell walls. In "Biology of the Red Algae", ed. by K. M. Cole and R. G. Sheath, Cambridge University Press, New York, pp. 227-233

Craigie, J. S. and C. Leigh 1978 Carrageenans and agars. In "Handbook of Phycological Methods; Phycological and Biochemical Methods", ed. by J. A. Hellebust and J. S. Craigie, Cambridge University Press, New York, pp. 109-131

Fujiki, K., H. Matsuyama and T. Yano 1993 Effect of hot-water extracts from marine algae on resistance of carp and yellowtail against bacterial infections. Sci. Bull. Fac. Agr., Kyushu Univ., 47: 137-141

Kawai, Y., N. Seno and K. Anno 1969 A modified method for chondrosulfatase assay. Anal. Biochem., 32: 314-321

Mangindaan, R. E. P. 1992 Protective effect of $\beta-1,3$-glucans against bacterial infections in carp and yellowtail. Ph. D. thesis, Kyushu University, Japan,.

McCandless, E. L., J. A. West and M. D. Guiry 1983 Carrageenan patterns in the Gigartinaceae. Biochem. System. Ecol. 11: 175-182

Painter, T. J. 1965 Isolation of $\kappa$-carrageenan from red algae. In "Methods in Carbohydrate Chemistry", Vol. 5, ed. by R. L. Whistler, Academic Press, New York, pp. 98-100

Robertsen, B., G. Røstad, R. Engstad and J. Raa 1990 Enhancement of non-specific disease resistance in Atlantic salmon, Salmo salar L., by a glucan from Saccharomyces cerevisiae cell walls. J. Fish Dis., 13: $391+400$

Yano, T., R. E. P. Mangindaan and H. Matsuyama 1989 Enhancement of the resistance of carp Cyprinus carpio to experimental Edwardsiella tarda infection, by some $\beta$-1,3-glucans. Nippon Suisan Gakkaishi, 55: $1815-1819$

Yano, T., H. Matsuyama and R. E. P. Mangindaan 1991 Polysaccharide-induced protection of carp, Cyprinus carpio L., against bacterial infection. J. Fish Dis., 14: 577-582

Yaphe, W. and G. P. Arsenault 1965 Improved resorcinol reagent for the determination of fructose, and of 3,6-anhydrogalactose in polysaccharides. Anal. Biochem., 13: 143-148 